\title{
Influence of some climate and soil conditions on tribenuron methyl activity depending on rate and adjuvant
}

\author{
Wpływ niektórych warunków klimatycznych i glebowych \\ na działanie tribenuronu metylu w zależności od dawki i adiuwanta
}

\author{
Renata Kieloch
}

\section{Summary}

The controlled environment experiments were carried out to evaluate the activity of tribenuron methyl applied under different climate and soil conditions depending on herbicide rate and application method. The herbicide was applied at two doses (15 and $7.5 \mathrm{~g} / \mathrm{ha}$ ), single and in the mixture with adjuvant Trend $90 \mathrm{EC}$. It was applied against plants of Anthemis arvensis L. and Papaver rhoeas L. that differed in plant moisture status (dry and wet plants) and type of soil (black soil and podsolic soil). Plant moisture status at the time of herbicide treatment differentiated activity of tribenuron methyl applied as single dosage against examined weed species, especially $P$. rhoeas. Greater efficacy was obtained when plants were wet during application time. Joint application of herbicide and adjuvant overcame differences in herbicide efficacy related to plant moisture status. Tribenuron methyl applied against both weed species growing on black soil was highly effective, independently on dose and application method. Weeds growing on podsolic soil were less controlled by herbicide used at single dosage than in the mixture with adjuvant. Differences in dose activity were observed, especially in the case of single application.

Key words: tribenuron methyl; adjuvant; herbicide dose; biomass reduction; Anthemis arvensis L.; Papaver rhoeas L.; plants wetting status; soil type

\section{Streszczenie}

Doświadczenia w warunkach kontrolowanych wykonano w celu oceny działania tribenuronu metylu stosowanego w różnych warunkach klimatycznych i glebowych w zależności od dawki środka oraz sposobu aplikacji. Herbicyd zastosowano w dwóch dawkach (15 i 7,5 g/ha), oddzielnie oraz łącznie z dodatkiem adiuwanta Trend 90 EC. Aplikowano go na rośliny Anthemis arvensis L. i Papaver rhoeas L. charakteryzujące się różnym stopniem uwilgotnienia (rośliny suche i wilgotne) oraz glebowych (czarna ziemia, gleba płowa). Stan uwilgotnienia roślin w momencie wykonywania zabiegu zróżnicował działanie tribenuronu metylu stosowanego samodzielnie w stosunku do badanych gatunków chwastów, a zwłaszcza P. rhoeas. Wyższą skuteczność osiągnięto, gdy w momencie wykonywania zabiegu rośliny były wilgotne. Łączna aplikacja herbicydu z adiuwantem zniwelowała różnice $w$ jego skuteczności w zależności od stanu uwilgotnienia roślin. Tribenuron metylu zastosowany na oba gatunki rosnące na czarnej ziemi wykazał wysoką skuteczność, niezależnie od wysokości dawki oraz sposobu aplikacji. Herbicyd stosowany samodzielnie na glebie płowej niszczył chwasty słabiej niż zastosowany $z$ adiuwantem. Wykazano różnice $w$ działaniu badanych dawek środka, zwłaszcza w przypadku samodzielnej aplikacji.

Słowa kluczowe: tribenuron metylu; adiuwant; dawka herbicydu; redukcja biomasy; Anthemis arvensis L.; Papaver rhoeas L.; stan uwilgotnienia roślin; typ gleby

Instytut Uprawy Nawożenia i Gleboznawstwa - Państwowy Instytut Badawczy

Zakład Herbologii i Technik Uprawy Roli

Orzechowa 61, 50-540 Wrocław

r.kieloch@iung.wroclaw.pl 


\section{Wstęp / Introduction}

Skuteczność danego herbicydu zależy głównie od jego właściwości fizykochemicznych, ale może być w znacznym stopniu modyfikowana przez warunki siedliskowe. Zmiany w skuteczności herbicydów pod wpływem warunków środowiska są związane z ich retencją pobieraniem, przemieszczaniem i rozkładem w tkankach roślin (Chachalis i wsp. 2001; Coetzer i wsp. 2001; Petersen i Hurle 2001). Procesy te odgrywają kluczową rolę w kształtowaniu końcowego efektu działania środka chwastobójczego.

Niekorzystny wpływ warunków siedliskowych na skuteczność herbicydów może być w znacznym stopniu ograniczony dzięki łącznej aplikacji z adiuwantami. Głównym zadaniem adiuwantów jest poprawa skuteczności działania herbicydu, przez wzrost retencji i absorpcji środków, co jest możliwe dzięki temu, że powodują one zmniejszenie napięcia powierzchniowego kropel cieczy użytkowej oraz dokładniejsze pokrycie opryskiwanej powierzchni (Praczyk i wsp. 2008; Aliverdi i wsp. 2009). Ponadto adiuwanty zapobiegają krystalizacji cieczy użytkowej na powierzchni roślin oraz opóźniają jej wysychanie, powodują zwiększenie przyczepności i rozpuszczalności herbicydu oraz lepsze uwodnienie kutykuli (Praczyk 2001; Wang i Liu 2007).

W kształtowaniu końcowego efektu działania herbicydu znaczącą rolę odgrywa wysokość zastosowanej dawki. Dobór dawki herbicydu ma istotne znaczenie nie tylko dla jego skuteczności chwastobójczej, ale także dla środowiska naturalnego. Stosowanie herbicydu w dawce niższej niż zaleca producent jest uzależnione od szeregu czynników, które wpływają na jego efektywność. Generalnie, obniżone dawki herbicydu powinno stosować się w warunkach sprzyjających jego działaniu (Domaradzki 2006). Z tego względu redukcja dawki środka nie zawsze jest uzasadniona i wymaga uprzedniego przeprowadzenia szeregu badań uwzględniających możliwie największą ilość czynników mogących determinować jego działanie.

Tribenuron metylu jest substancją czynną herbicydów z grupy inhibitorów enzymu ALS (acetolactate synthase syntetaza acetylomleczanowa), powszechnie stosowaną do zwalczania chwastów dwuliściennych w zbożach. W celu osiagnnięcia wysokiej skuteczności zaleca się stosować go łącznie $\mathrm{z}$ adiuwantami.

Celem badań była ocena działania tribenuronu metylu stosowanego w zróżnicowanych warunkach stanu uwilgotnienia roślin i na różnych typach gleb w zależności od wysokości jego dawki oraz sposobu aplikacji.

\section{Materiały i metody / Materials and methods}

Badania przeprowadzono w komorach klimatycznych MLR-350 HT i MLR-350 firmy SANYO w Zakładzie Herbologii i Technik Uprawy Roli Instytutu Uprawy Nawożenia i Gleboznawstwa - Państwowego Instytutu Badawczego we Wrocławiu. W ramach badań wykonano dwa rodzaje doświadczeń: 1. ocena wpływu stanu uwilgotnienia roślin (rosy) na działanie tribenuronu metylu,
2. ocena wpływu typu gleby na działanie tribenuronu metylu. W obu doświadczeniach uwzględniono dwa gatunki chwastów - Anthemis arvensis L. i Papaver rhoeas L., których nasiona pochodziły $\mathrm{z}$ pól zlokalizowanych w okolicach Wrocławia, z poletek nietraktowanych herbicydami. Nasiona chwastów wysiano na głębokość $0,5 \mathrm{~cm}$ do doniczek o średnicy $8 \mathrm{~cm}$ wypełnionych odpowiednim podłożem, w zależności od badanego czynnika. Doniczki podlewano codziennie przez cały okres prowadzenia doświadczeń. Dzień przed planowanym opryskiwaniem wykonano przerywkę, zostawiając po 4 sztuki roślin w każdej doniczce.

Tribenuron metylu zastosowano w dawce zalecanej (15 g/ha) oraz zredukowanej $(7,5 \mathrm{~g} / \mathrm{ha}) \mathrm{w}$ formie herbicydu Granstar 75 WG. Środek aplikowano oddzielnie oraz łącznie $\mathrm{z}$ dodatkiem adiuwanta Trend 90 EC (etoksylowany alkohol izodecylowy $90 \%$ ) w dawce $0,05 \%$.

Aplikację herbicydu przeprowadzono w komorze opryskowej „Aporo” wyposażonej w ruchomą dyszę (TeeJet XR 11003-VS) pracującą pod ciśnieniem roboczym $200 \mathrm{kPa}$, zapewniającą wydatek cieczy użytkowej 250 1/ha. Zabieg wykonano w fazie 2-4 liści chwastów.

Skuteczność zabiegów oceniono na podstawie ubytku świeżej masy chwastów pod wpływem działania herbicydu. Analizę wykonano po upływie 3 tygodni od przeprowadzenia zabiegu. Obliczenia statystyczne wykonano uwzględniając dane wyrażone w \%, przekształcone według wzoru Blissa. Obliczenia przeprowadzono w następującym układzie: doświadczenia dwuczynnikowe, gdzie jednym z czynników doświadczenia był czynnik abiotyczny, natomiast jako drugi czynnik potraktowano kombinacje obiektów herbicydowych $\times$ dawki wraz $\mathrm{z}$ obiektem kontrolnym.

\section{Doświadczenie nr 1}

Nasiona chwastów wysiano do doniczek wypełnionych mieszaniną torfu i piasku w stosunku objętościowym 2:1. Bezpośrednio po siewie doniczki umieszczono w komorach klimatycznych, gdzie temperatura powietrza wynosiła $20 / 10^{\circ} \mathrm{C}$ w układzie dzień/noc, a natężenie światła 10000 lx. Fotoperiod wynosił 14 godzin dnia i 10 godzin nocy. Doniczki były podlewane codziennie. Bezpośrednio przed aplikacją herbicydów doniczki z każdym gatunkiem chwastu podzielono na dwie równe grupy. Pierwszą umieszczono $\mathrm{w}$ komorze opryskowej i potraktowano czystą wodą, aby uzyskać efekt zwilżonych powierzchni blaszek liściowych. Do aplikacji wody wykorzystano dyszę płaskostrumieniową TeeJet XR 11003-VS, a zabieg wykonano z prędkością $2,5 \mathrm{~km} / \mathrm{h}$ i ciśnieniem roboczym $200 \mathrm{kPa}$. Po wykonaniu zabiegu, aż do zbioru chwastów powierzchnie ich blaszek liściowych utrzymywane były w stanie suchym. Rośliny rosnące w drugiej grupie doniczek miały suchą powierzchnię blaszek liściowych i w takim stanie zostały potraktowane herbicydami.

\section{Doświadczenie nr 2}

Do badań wykorzystano dwa typy gleb: 1. gleba płowa zaliczana do kompleksu żytniego słabego, wytworzona na 
Tabela 1. Charakterystyka gleb użytych w doświadczeniach

Table 1. Characteristic of soilsused in experiments

\begin{tabular}{|c|c|c|c|}
\hline \multirow{2}{*}{\multicolumn{2}{|c|}{ Parametr - Parameter }} & \multicolumn{2}{|c|}{ Typ gleby - Soil type } \\
\hline & & gleba płowa - podsolic soil (6Aps) & czarna ziemia - black soil (1Dgs) \\
\hline \multicolumn{2}{|l|}{$\mathrm{pH}$} & 4,60 & 6,05 \\
\hline \multirow{4}{*}{ 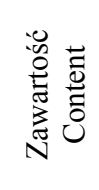 } & $\mathrm{C}[\%]$ & 1,25 & 2,35 \\
\hline & $\mathrm{P}_{2} \mathrm{O}_{5}[\mathrm{mg} / 100$ g p.s.m. - dry matter] & 18,5 & 17,1 \\
\hline & $\mathrm{K}_{2} \mathrm{O}$ [mg/100 g p.s.m. - dry matter] & 13,0 & 32,0 \\
\hline & $\mathrm{Mg}$ [mg/100 g p.s.m. - dry matter] & 3,7 & 12,5 \\
\hline
\end{tabular}

piasku słabo gliniastym (6Aps), 2. czarna ziemia zaliczana do kompleksu pszennego bardzo dobrego, wytworzona na glinie średniej (1Dgs). Charakterystykę obu gleb przedstawiono $\mathrm{w}$ tabeli 1 . Pobrano je $\mathrm{z}$ pól, na których nie stosowano herbicydów długo zalegajacych w glebie, aby uniknąć ich następczego oddziaływania na rośliny. Glebę w każdej doniczce dokładnie wymieszano z wodą, aby osiagnąć $60 \%$ wilgotności. W tak przygotowane podłoże wysiano nasiona chwastów, a doniczki umieszczono w komorach klimatycznych, w których panowały warunki termiczne i świetlne, takie jak dla doświadczenia nr 1.

\section{Wyniki i dyskusja / Results and discussion}

A. arvensis charakteryzował się wysoką wrażliwością (86-97\% ubytku świeżej masy) na aplikację tribenuronu metylu, stosowanego oddzielnie, jak i łącznie $\mathrm{z}$ adiuwantem, niezależnie od jego dawki oraz stanu uwilgotnienia roślin. Istotny statystycznie spadek skuteczności obserwowano, gdy tribenuron metylu zastosowano oddzielnie w dawce zredukowanej na rośliny suche. Nie mniej jednak uzyskany rezultat hamowania wzrostu roślin pozwalał nadal zaliczyć go do gatunków wrażliwych (tab. 2a).

Rośliny $P$. rhoeas były wysoce wrażliwe (94-99\% ubytku świeżej masy) na tribenuron metylu aplikowany oddzielnie oraz łącznie $\mathrm{z}$ adiuwantem, niezależnie od użytej dawki, gdy rośliny w momencie wykonywania zabiegu były wilgotne. Również wysoki stopień wrażliwości osiągnięto po zastosowaniu mieszanin herbicydu (bez względu na jego dawkę) $\mathrm{z}$ adiuwantem na rośliny suche (redukcja biomasy o 87-96\%). W przypadku oddzielnej aplikacji herbicydu na rośliny suche nastąpił znaczący

Tabela 2. Wpływ dodatku adiuwantów na skuteczność tribenuronu metylu w ograniczaniu świeżej masy chwastów, w zależności od stanu uwilgotnienia roślin w czasie zabiegu

Table 2. Influence of adjuvants addition on tribenuron methyl activity in weed fresh weight reduction, in relation to plant moisture status during herbicide treatment

a. A. arvensis

\begin{tabular}{|c|c|c|c|}
\hline \multirow{2}{*}{ Obiekty - Objects } & \multirow{2}{*}{$\begin{array}{l}\text { Dawki/ha } \\
\text { Doses/ha }\end{array}$} & \multicolumn{2}{|c|}{$\begin{array}{c}\text { Redukcja biomasy - Biomass reduction } \\
{[\%]}\end{array}$} \\
\hline & & $\begin{array}{l}\text { rośliny suche } \\
\text { dry plants }\end{array}$ & $\begin{array}{l}\text { rośliny wilgotne } \\
\text { wet plants }\end{array}$ \\
\hline \multirow{2}{*}{ Tribenuron methyl } & $15 \mathrm{~g}$ & $90 \mathrm{~b}$ & $95 \mathrm{a}$ \\
\hline & $7,5 \mathrm{~g}$ & $86 \mathrm{~b}$ & $90 \mathrm{a}$ \\
\hline \multirow{2}{*}{ Tribenuron metyl + adiuwant - adjuvant } & $15 \mathrm{~g}+0,05 \%$ & $95 \mathrm{a}$ & $97 \mathrm{a}$ \\
\hline & $7,5 \mathrm{~g}+0,05 \%$ & $95 \mathrm{a}$ & $92 \mathrm{a}$ \\
\hline
\end{tabular}

Wartości oznaczone tymi samymi literami nie różnią się istotnie - Values marked by the same letters do not differ significantly

b. P. rhoeas

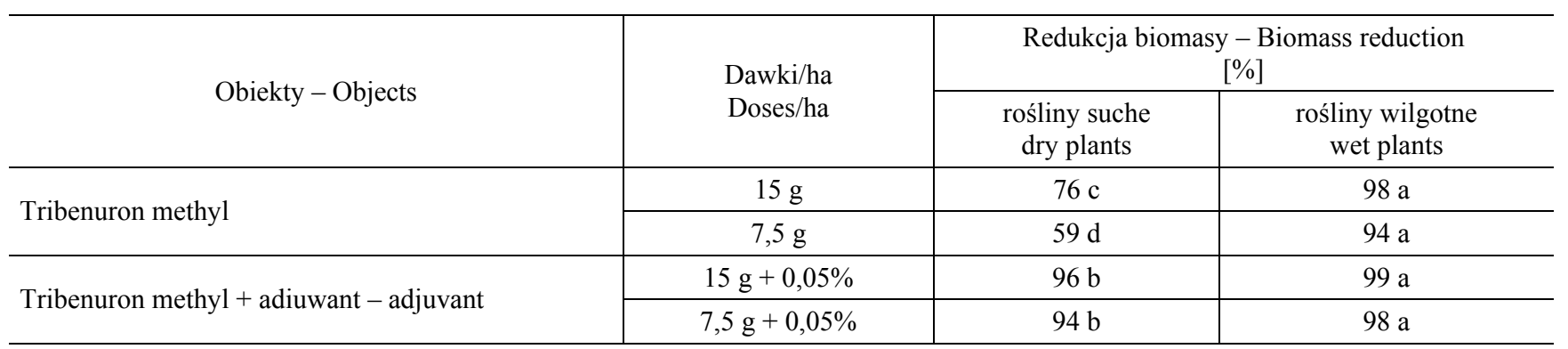

Wartości oznaczone tymi samymi literami nie różnią się istotnie - Values marked by the same letters do not differ significantly 
spadek skuteczności do poziomu średniego (hamowanie wytwarzania biomasy o 76\%) dla dawki zalecanej oraz niskiego (59\% redukcji świeżej masy) dla dawki obniżonej (tab. 2b).

Rośliny $A$. arvensis rosnące na czarnej ziemi, jak i na glebie płowej były wrażliwe (redukcja biomasy o 86-96\%) na tribenuron metylu zastosowany oddzielnie, jak również łącznie $\mathrm{z}$ adiuwantem, niezależnie od wysokości dawki. Wykonana analiza statystyczna wykazała jednak istotne różnice $\mathrm{w}$ skuteczności działania tribenuronu metylu na glebie płowej pomiędzy obiektami, na których herbicyd aplikowano w mieszaninie i samodzielnie. Również na obiekcie bez dodatku adiuwanta wystapiły istotne różnice w reakcji roślin w zależności od dawki herbicydu (tab. 3a). Rośliny $P$. rhoeas rosnące na czarnej ziemi były niszczone w 94-98\% przez tribenuron metylu, bez względu na sposób jego aplikacji oraz wysokość dawki. W przypadku chwastów rosnących na glebie płowej, ich wrażliwość była wysoka w stosunku do mieszaniny herbicydu $\mathrm{z}$ adiuwantem, niezależnie od dawki środka. Zanotowano jednak istotne statystycznie różnice $\mathrm{w}$ działaniu pomiędzy dawką zalecaną a obniżoną. Rośliny potraktowane herbicydem bez dodatku adiuwanta, $w$ dawce zalecanej były redukowane $\mathrm{w} 83 \% \mathrm{w}$ powyższych warunkach glebowych, czyli istotnie słabiej niż na czarnej ziemi. Po aplikacji dawki obniżonej nastąpił istotny spadek redukcji biomasy tego gatunku do poziomu $65 \%$ (tab. $3 b$ ).

Czynniki klimatyczne i glebowe mogą w znaczący sposób kształtować skuteczność herbicydów. Stan uwilgotnienia roślin $\mathrm{w}$ momencie wykonywania zabiegu chwastobójczego wpływa na ilość pobranego środka. Wilgotna powierzchnia liści powoduje, że kutikula jest lepiej uwodniona i tym samym bardziej przepuszczalna dla herbicydów. $Z$ drugiej strony krople rosy na powierzchni blaszek liściowych moga przyczyniać się do rozcieńczenia i spływania aplikowanego herbicydu, co prowadzi do spadku skuteczności (Caseley 1989; Roman i wsp. 2004). Prace dotyczace wpływu stanu uwilgotnienia roślin na działanie środków chwastobójczych są rzadko spotykane w literaturze, $\mathrm{z}$ tego względu, że generalnie zaleca się unikać opryskiwania roślin mokrych. W dodatku opracowania te daja rozbieżne wnioski, co w konsekwencji nie pozwala jednoznacznie stwierdzić, jak czynnik ten kształtuje efektywność herbicydów. W niniejszej pracy obecność rosy okazała się czynnikiem poprawiającym działanie tribenuronu metylu, zwłaszcza gdy stosowano go oddzielnie. Można również zaobserwować różnice gatunkowe, gdzie $P$. rhoeas był gatunkiem, którego wrażliwość na badany środek $w$ większym stopniu zależała od testowanego czynnika niż wykazano to dla $A$. arvensis. Dodatni wpływ rosy na działanie niektórych herbicydów (difenzokwatu, barbanu i bentazonu) został również wykazany w badaniach Adamczewskiego (1976), przy czym był on uzależniony od wilgotności powietrza i rodzaju herbicydu.

W prezentowanych badaniach uwzględniono dwa typy gleb - zasobną w próchnicę i składniki pokarmowe czarną ziemię oraz mniej zasobną, zwłaszcza pod względem materii organicznej oraz fosforu i potasu - glebę płową. Trudno jest jednoznacznie określić przyczynę nieco

Tabela 3. Wpływ dodatku adiuwantów na skuteczność tribenuronu metylu w ograniczaniu świeżej masy chwastów na różnych typach gleb

Table 3. Influence of addition of adjuvants on tribenuron methyl activity in weed fresh weight reduction under different type of soil

a. A. arvensis

\begin{tabular}{l|c|c|c}
\hline \multirow{2}{*}{ Obiekty - Objects } & \multirow{2}{*}{$\begin{array}{c}\text { Redukcja biomasy - Biomass reduction } \\
\text { [\%wi/ha } \\
\text { Doses/ha }\end{array}$} & $\begin{array}{c}\text { czarna ziemia } \\
\text { black soil }\end{array}$ & $\begin{array}{c}\text { gleba płowa } \\
\text { podsolic soil }\end{array}$ \\
\cline { 2 - 4 } Tribenuron methyl & $15 \mathrm{~g}$ & $95 \mathrm{a}$ & $89 \mathrm{~b}$ \\
\hline \multirow{2}{*}{ Tribenuron methyl + adiuwant - adjuvant } & $7,5 \mathrm{~g}$ & $92 \mathrm{a}$ & $86 \mathrm{c}$ \\
\cline { 2 - 4 } & $15 \mathrm{~g}+0,05 \%$ & $97 \mathrm{a}$ & $97 \mathrm{a}$ \\
\cline { 2 - 4 } & $7,5 \mathrm{~g}+0,05 \%$ & $94 \mathrm{a}$ & $95 \mathrm{a}$ \\
\hline
\end{tabular}

Wartości oznaczone tymi samymi literami nie różnią się istotnie - Values marked by the same letters do not differ significantly

b. P. rhoeas

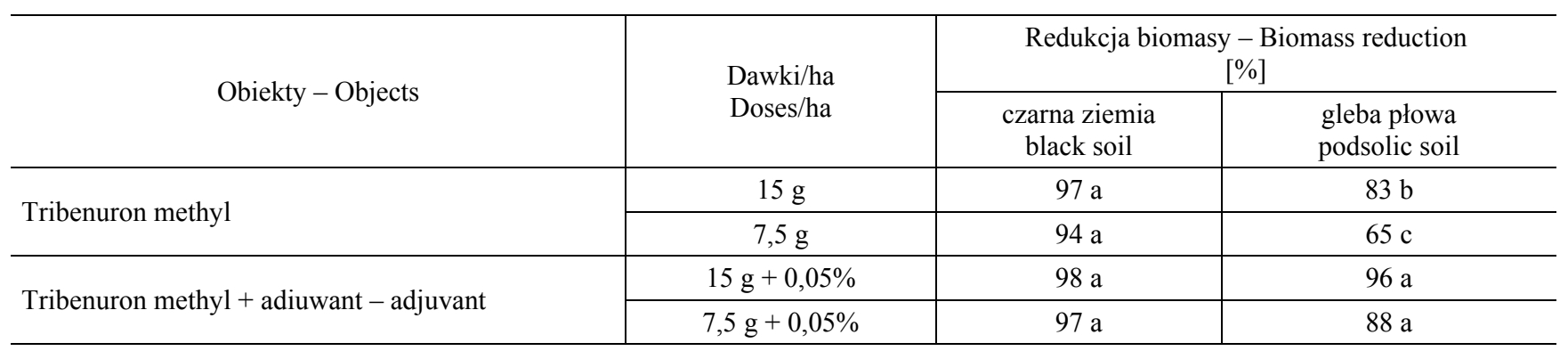

Wartości oznaczone tymi samymi literami nie różnią się istotnie - Values marked by the same letters do not differ significantly 
lepszego działania herbicydów stosowanych na czarnej ziemi, tym bardziej, że nie znaleziono prac dotyczących wpływu typu gleby na skuteczność herbicydów stosowanych nalistnie. Tribenuron metylu, pomimo że przeznaczony jest do nalistnej aplikacji, może być w ograniczonym stopniu pobierany przez korzenie, co jest zależne między innymi od właściwości gleby, a ściślej mówiąc zawartości materii organicznej (Rutherford i wsp. 1992). $\mathrm{Na}$ glebach o dużej zawartości próchnicy środki chwastobójcze są silnie absorbowane przez glebę, co może być przyczyną ich słabszego działania na chwasty (Heitefuss 1979; Bernard i wsp. 2005). Z drugiej strony na glebach cięższych rośliny są w lepszej kondycji i z tego powodu powinny być mniej podatne na działanie herbicydów, co jednak nie jest zgodne $\mathrm{z}$ wynikami przeprowadzonego doświadczenia. Czarne ziemie są glebami bardziej zasobnymi w azot, co może sugerować zbieżność z wynikami badań Mithila i wsp. (2008), którzy dowiedli spadek skuteczności glifosatu w warunkach niskiego zaopatrzenia gleby $\mathrm{w}$ ten pierwiastek. Wyjaśnienie tego zagadnienia wymaga jednak bardziej szczegółowych badań odnośnie wpływu poszczególnych cech obu gleb, tj. pH, zasobności w składniki pokarmowe i zawartości substancji organicznej na skuteczność herbicydów stosowanych nalistnie.

Rezultaty przeprowadzonych doświadczeń wskazują, że tribenuron metylu można $\mathrm{z}$ zadowalającym skutkiem stosować $\mathrm{w}$ dawce zredukowanej o połowę w stosunku do zalecanej, gdy zabieg wykonuje się w optymalnych warunkach glebowych i klimatycznych. Podobne rezultaty uzyskał Collings i wsp. (2003) twierdząc, że wpływ przebiegu pogody jest bardziej wyraźny, gdy herbicydy stosuje się w dawkach niższych niż zalecane. Obserwowany w badaniach niekorzystny wpływ warunków klimatycznoglebowych na skuteczność tribenuronu metylu dotyczy jedynie samodzielnej aplikacji środka. Skutkuje ona istotnym spadkiem efektywności oraz wystapieniem znaczących różnic $\mathrm{w}$ działaniu obu dawek na glebie płowej oraz gdy opryskiwane powierzchnie roślin są suche. W związku z powyższym dodatek adiuwantów pełni znaczącą rolę w utrzymaniu efektywności zabiegu na wysokim poziomie, niezależnie od warunków środowiskowych lub zastosowanej dawki (Kudsk i Mathiassen 2007). Poprawę działania tribenuronu metylu dzięki łącznej aplikacji $\mathrm{z}$ adiuwantem przedstawiono już we wcześniejszych pracach (Stagnari i wsp. 2007; Aliverdi i wsp. 2009). Ponadto autorzy wykazali różnice gatunkowe w reakcji na ten środek, co również zostało wykazane w prezentowanej pracy. Dodatek adiuwantów pozwala na zachowanie wysokiej skuteczności herbicydów stosowanych również $w$ dawce niższej niż zalecana (Collins i Helling 2002; Stagnari i wsp. 2006). Uzyskane wyniki badań potwierdzają także tę prawidłowość. Łączne zastosowanie tribenuronu metylu $\mathrm{z}$ adiuwantem pozwoliło na znaczne zmniejszenie lub całkowite zniwelowanie różnic pomiędzy dawką zalecaną a obniżoną w warunkach mniej korzystnych dla działania herbicydu, tj. w przypadku roślin rosnących na słabszej glebie oraz gdy powierzchnie blaszek liściowych były suche. Wykonane badania wskazują również, że dodatek adiuwanta pozwala ograniczyć różnice $\mathrm{w}$ skuteczności środka wynikające $\mathrm{z}$ wpływu warunków środowiskowych, co zostało również opisane we wcześniejszych pracach (Mathiassen i Kudsk 2002; Kieloch 2006).

\section{Wnioski / Conclusions}

1. Stan uwilgotnienia roślin w momencie wykonywania zabiegu zróżnicował działanie tribenuronu metylu stosowanego oddzielnie w stosunku do badanych gatunków chwastów, a zwłaszcza $P$. rhoeas. Wyższą skuteczność osiagnięto, gdy w momencie wykonywania zabiegu rośliny były wilgotne.

2. Łączna aplikacja herbicydu z adiuwantem pozwoliła ograniczyć różnice $\mathrm{w}$ jego skuteczności w zależności od stanu uwilgotnienia roślin.

3. Tribenuron metylu zastosowany na rośliny obu gatunków chwastów rosnących na czarnej ziemi wykazał wysoką skuteczność, niezależnie od wysokości dawki oraz sposobu aplikacji.

4. Badany herbicyd aplikowany oddzielnie na glebie płowej wykazał znacznie słabsze działanie niż zastosowany łącznie $\mathrm{z}$ adiuwantem. W powyższych warunkach glebowych stwierdzono spadek skuteczności środka zastosowanego w dawce zredukowanej, zwłaszcza w przypadku samodzielnej aplikacji.

Opracowanie wykonano w ramach zadania $2.6 \mathrm{w}$ Programie Wieloletnim Instytutu Uprawy Nawożenia i Gleboznawstwa - Państwowego Instytutu Badawczego.

\section{Literatura / References}

Adamczewski K. 1976. Wpływ rosy na efekt chwastobójczy przy stosowaniu barbanu, difenzoquatu i bentazonu. Rocz. Nauk Rol. Seria A, 102 (1): 29-39.

Aliverdi A., Mohassel M.H.R., Mahallati M.N. 2009. Increased foliar activity of clodinafop-propargyl and/or tribenuron-methyl by surfactants and their synergistic action on wild oat (Avena ludoviciana) and wild mustard (Sinapis arvensis). Weed Biol. Manage. 9 (4): 292-299.

Bernard H., Chabalier P.F., Chopart J.F., Legube B., Vauclin M. 2005. Assessment of herbicide leaching risk in two tropical soils of Reunion Island (France). J. Environ. Qual. 34 (2): 534-543.

Caseley J.C. 1989. Variations in foliar pesticide performance attributable to humidity, dew and rain effects. Aspects Appl. Biol. 21: $215-225$.

Chachalis D., Reddy K.N., Elmore C.D., Steele M.L. 2001. Herbicide efficacy, leaf structure, and spray droplet contact angle among Ipomoea species and smallflower morningglory. Weed Sci. 49 (5): 628-634. 
Coetzer E., Al-Khatib K., Loughin T.M. 2001. Glufosinate efficacy, absorption and translocation in amaranth as affected by relative humidity and temperature. Weed Sci. 49 (1): 8-13.

Collings L.V., Blair A.M., Gay A.P., Dyer C.J., Mackay N. 2003. The effect of weather factors on the performance of herbicides to control Alopecurus myosuroides in winter wheat. Weed Res. 43 (2): 146-153.

Collins R.T., Helling C.S. 2002. Surfactant - enhanced control of two Erythroxylum species by glyphosate. Weed Technol. 16 (4): $851-859$

Domaradzki K. 2006. Efektywność regulacji zachwaszczenia zbóż w aspekcie ograniczania dawek herbicydów oraz wybranych czynników agroekologicznych. Pam. Puł., Monografie i Rozprawy Naukowe 17, 111 ss.

Heitefuss R. 1979. Podstawy ochrony roślin. PWRiL, Warszawa, 312 ss.

Kieloch R. 2006. Wpływ adiuwantów na skuteczność tribenuronu metylu stosowanego w różnych warunkach temperatury i wilgotności względnej powietrza. [An influence of adjuvants on effectivenes of tribenuron-methyl applied in various temperature and relative humidity conditions]. Prog. Plant Prot./Post. Ochr. Roślin 46 (1): 240-246.

Kudsk P., Mathiassen S.K. 2007. Analysis of adjuvants effects and their interactions with variable applications parameters. Crop Prot. 26 (3): 328-334.

Mathiassen S.K., Kudsk P. 2002. The influence of adjuvants on the efficacy and rainfastness of iodosulfuron. p. 206-207. Proc. 12th EWRS Symposium. Netherlands, Arnhem, 24-27 June 2002. European Weed Research Society, Doorwerth, the Netherland, 438 pp.

Mithila J., Swanton C.J., Blackshaw R.E., Cath-Cart R.J., Hall J.C. 2008. Physiological basis for reduced glyphosate efficacy on weeds grown under low soil nitrogen. Weed Sci. 56 (1): 12-17.

Petersen J., Hurle K. 2001. Influence of climatic conditions and plant physiology on glufosinate-ammonium efficacy. Weed Res. 41 (1): 31-39.

Praczyk T. 2001. Rozwój badań i zastosowań adiuwantów w Polsce. [Progress in research and application of adjuvants in Poland]. Prog. Plant Prot./Post. Ochr. Roślin 41 (1): 110-113.

Praczyk T., Bączkowska E., Balcer G., Kulczyński J., Dorna J. 2008. Nowy adiuwant wspomagający aktywność niektórych herbicydów i fungicydów. [New adjuvant improving activity of some herbicides and fungicides]. Prog. Plant Prot./Post. Ochr. Roślin 48 (2): $647-652$.

Roman E.S., Vargas L., Ribeiro M.C.F. 2004. Influence of dew and spray volume on the efficacy of glyphosate for Brachiaria plantaginea burndown. Planta Daninha 22 (3): 479-482.

Rutherford D.W., Chiou C.T., Kile E.D. 1992. Influence of soil organic matter composition on the partition of organic compounds. Environ. Sci. Technol. 26 (2): 336-340.

Stagnari F., Chiarini M., Pisante M. 2007. Influence of fluorinated surfactants on the efficacy of some post-emergence sulfonylurea herbicides. J. Pest. Sci. 32 (1): 16-23.

Stagnari F., Onfori A., Covarelli G. 2006. Influence of vegetable oils on the efficacy of some post-emergence herbicides for grass weed control in wheat. J. Pest. Sci. 31 (3): 339-343.

Wang C.J., Liu Z.Q. 2007. Foliar uptake of pesticides - Present status and future challenge. Pest. Biochem. Physiol 87 (1): 1-8. 